\title{
Ciência da Computação, Ciência da Informação, Sistemas de Informação: uma reflexão sobre o papel da informação e da interdisciplinaridade na configuração das tecnologias e das ciências
}

Isabel Cafezeiro

Professora Associada IIII do Departamento de Ciência da Computação Universidade Federal Fluminense.Pós Doutora pelo Programa de História das Ciências e das Técnicas e Epistemologia da UFRJDoutora em Informática PUC-Rio

Leonardo Cruz da Costa

Vice-Coordenador do Programa de Pós-Graduação em Ciência da Informação da Universidade Federal Fluminense.Professor Associado do Instituto de Computação da Universidade Federal Fluminense Coordenador do Curso de Graduação em Sistemas de Informação da Universidade Federal Fluminense

Ricardo da Silva Kubrusly

Professor Titular do Programa de Pós-Graduação em História das Ciências e das Técnicas e Epistemologia da Universidade Federal do Rio de Janeiro

http://dx.doi.org/10.1590/1981-5344/2681

A partir de uma abordagem histórica do percurso de construção do computador e da computação, argumentamos em favor de uma interação mais vigorosa entre as Ciências da Computação e da Informação. Os argumentos se estabelecem não somente em torno da constatação do papel da informação como conformadora de ambas as áreas, mas também a partir de evidências da impossibilidade dos saberes ditos "exatos" ou dos saberes ditos "humanos" resolverem por si só os desafios que se fizeram presentes na construção das ciências e tecnologias. Além disso, verifica-se o hibridismo entre 
aquilo que se designa "conteúdo" (o que se estuda) e o que se designa "contexto" (onde e quando se estuda), e a impossibilidade de uma compreensão ampla de artefatos tecnológicos ou fatos científicos de maneira dissociada das condições históricas onde foram elaborados. $O$ conjunto destas três questões deixa evidente que, assim como a Ciência da Informação, a também a Ciência da Computação se conforma na informação, e portanto, o diálogo entre estes campo necessita almejar o nível de co-construção de ambos os campos.

Palavras-chaves: Ciência da Computação; Ciência da Informação; Sistemas de Informação; Intedisciplinaridades

\section{Computer Science, Information Science, Information Systems: A reflection on the role of information and interdisciplinarity in the configuration of technologies and sciences}

From a historical approach of the construction of the computer and computing, we argue in favor of a more vigorous interaction between Computer Science and Information Science. The arguments are established not only around the role of information as performer of both areas, but also from evidence of the impossibility of "exact" or "human" knowledge to solve by themselves the challenges of the construction of science and technology. In addition, we consider the hybridism between what is called "content" (what is studied) and the so-called "context" (where and when is studied), and the impossibility of a broad understanding of technological artifacts or scientific facts dissociated of the historical conditions in which they have been proposed. All these three questions make clear that, like the Science of Information, Computer Science is also constructed around the information, and therefore, the dialogue between these fields need to crave the level of co-construction of both fields. 
Keywords: Computer Science; Information Science; Information Systems; Intedisciplinarities.

Recebido em 07.01.2016 Aceito em 31.05.2016

\section{Introdução}

Óbvio ululante, expressão imortalizada por Nelson Rodrigues em uma coletânea de "confissões" (RODRIGUES, 1993), significa aquilo que não precisa ser dito. Todo mundo vê, todo mundo sabe, "tá na cara" que é assim. O óbvio é o que dispensa comentários. Porém acontece que, por ser demasiadamente evidente, nos acostumamos com ele, e assim, tornase despercebido. Passamos, então, de um extremo a outro: o que antes era por si próprio evidente, urge agora ser ressaltado. Aqui, para nós, evidente é o fato de que Ciência da Informação e Sistemas de Informação são campos de saber que, por abordarem o mesmo objeto, a informação, demandam co-operação (operação conjunta). Porém, quem atua nesses campos percebe o pouco (ou a ausência de) diálogo entre esses saberes. A história da institucionalização destes campos não somente explica este afastamento, como também ressalta a urgência de uma retomada nesta interação. Disse Benveniste, o linguista, referindo-se a uma outra evidência: "Por vezes é útil pedir à evidência que se justifique" (BENVENISTE, 1992). No que se segue, argumentamos, sob uma perspectiva histórica, que Ciência da Informação e Ciência da Computação, através do campo de Sistemas de Informação, se beneficiam na interação em torno do conceito de informação.

Aqueles de nós que contribuíram à nova ciência da 'Cibenética' estão, portanto, numa posição moral que é, para dizer o mínimo, não muito confortável. Nós contribuímos para o nascimento de uma nova ciência que, como eu disse, abraça desenvolvimentos tecnológicos para o bem e para o mal. Só podemos lidar com isso no mundo em que vivemos, e esse é o mundo de Belsen e Hiroshima. Não temos a escolha de suprimir esses novos avanços tecnológicos. Eles pertencem a essa era, e o máximo que qualquer um de nós pode fazer como supressão é colocar o desenvolvimento desse tema nas mãos dos mais irresponsáveis e mais venais de nossos engenheiros. $O$ melhor que nós podemos fazer é ver que um amplo público compreende as direções e o desenrolar desse trabalho, e concentrar nossos esforços naqueles campos, como fisiologia e psicologia, mais remotos à guerra e à exploração. Como vimos, há aqueles que esperam que os benefícios de um melhor entendimento do homem e da sociedade que é oferecido por este novo campo de trabalho antecipe e prevaleça à contribuição incidental que fazemos 
sobre a concentração do poder (que está sempre concentrado, por sua própria condição de existência, nas mãos dos mais inescrupulosos). Escrevo em 1947, e sou obrigado a dizer que é uma esperança muito remota. (WIENER, 1985, p. 28-29).

\section{Tecnologias, informação e guerra}

Iniciamos nossas reflexões a partir de cenas da guerra. O trauma do lançamento das bombas de Hiroshima e Nagasaki, dirigiu o olhar de um conjunto de cientistas para reflexões sobre as ciências e tecnologias, e as perspectivas de um mundo que vinha sendo construído na base de avanços tecnológicos recentes.

Não muito distante do ano de 1947 em que o matemático Norbert Wiener escreveu as linhas acima, o mundo presenciou as angústias de Albert Einstein com relação aos destinos das pesquisas científicas, e, mais precisamente, de suas contribuições relativas à compreensão da energia. Em 1939, Einstein, pacifista declarado, simpático ao socialismo, alemão, residente nos EUA por motivos de perseguições políticas, escreveu uma carta ao então Presidente Roosevelt alertando que as ciências já haviam alcançado um nível de desenvolvimento capaz de fabricar a bomba atômica e que a Alemanha de Hitler poderia ser a primeira nação a deter tal equipamento: "Tendo em vista esta situação, o senhor pode considerar adequado manter um contato permanente entre a administração e o grupo de físicos que trabalham nesta cadeia de reações na América". E propôs a Roosevelt "acelerar o trabalho experimental que, no presente, vem sendo conduzido dentro dos limites orçamentários dos laboratórios universitários" (EINSTEIN, 2016, s. p.). Agradecido, o presidente Roosevelt respondeu: "Considerei estes dados de tamanha importância que convoquei um Conselho constituído pelo chefe do 'Bureau of Standards' e um representante escolhido do Exército e da Marinha para investigar exaustivamente as possibilidades de sua sugestão sobre o elemento de urânio" (ROOSEVELT, 2016, s. p.).

A carta de Einstein parece ter sido o argumento motivador para a criação do Projeto Manhattann, o investimento dos Estados Unidos nos armamentos nucleares, que viria a desembocar nas bombas de Hiroshima e Nagasaki em 1945. Angustiado e imprensado entre o pânico de imaginar um mundo refém de Hitler e as consequências da corrida armamentista que o Projeto Manhattan viria a desencadear, Einstein prosseguiu sua militância em favor da humanidade. Pouco mais tarde declarou:

[...] $\mathrm{E}$, no entanto, sou apaixonadamente um pacifista e minha maneira de ver não é diferente diante da mortandade em tempo de paz. Já que as nações não se resolvem a suprimir a guerra por uma ação conjunta, já que não superam os conflitos por uma arbitragem pacífica e não baseiam seu direito sobre a lei, elas se vêem inexoravelmente obrigadas a preparar a guerra. Participando da corrida geral dos 
armamentos e não querendo perder, concebem e executam os planos mais detestáveis. Precipitam-se para a guerra. Mas hoje, a guerra se chama o aniquilamento da humanidade. (EINSTEIN,1981, p. 28)

Ao fim da segunda guerra, iniciou-se a guerra fria. Passados dez anos das bombas de Hiroshima e Nagazaki, em março de 1955 os Estados Unidos realizaram o primeiro teste da bomba de hidrogênio no Atol de Bikini. Ocorreu o inesperado: ventos de grande altitude levaram a poeira atômica para uma direção imprevista e a nuvem radioativa atingiu um navio pesqueiro japonês causando danos à tripulação: triste cenas de perecimento humano. Dentre os cientistas, intensificaram-se as manifestações pacifistas (BARROS, 2005).

No mesmo ano de 1955, Einstein veio a falecer no dia 18 de abril, em decorrência de aneurisma. Sete dias antes havia enviado uma carta ao filósofo matemático Bertrand Russell concordando com os termos de um manifesto que anunciava a urgência de interromper o uso e fabricação de armas atômicas. O manifesto Russell-Einstein contou ainda com a assinatura de outros 11 cientistas (EINSTEIN; RUSSELL, 2016). Após a morte de Einstein, o manifesto foi a público com ampla divulgação, conforme Russell havia planejado. Como resultado desencadeou a série de conferências Pugwash (http://pugwash.org/), que ainda nos dias de hoje discute o desarmamento nuclear e busca um mundo livre de armas de destruição em massa.

De forma diametralmente oposta procedeu von Neumann. Considerado hoje figura chave na invenção dos computadores, o húngaro John von Neumann, já era no início dos anos 1930 renomado matemático. Anti-comunista declarado, passou a residir nos Estados Unidos por motivos semelhantes aos de Einstein: a perseguição judaica. No ano de 1930 foi convidado a ingressar no Institute of Advaces Study (IAS, Princeton), onde já estava Einstein. No período da segunda guerra, diante do jogo de forças entre, de um lado, o apelo dos matemáticos e físicos humanistas e, de outro lado, o empenho do governo dos Estados Unidos em recrutar mentes brilhantes para o trabalho científico na produção de armamentos, von Neumann optou pelo segundo. Conta o físico Richard Feynman: "Von Neumann me deu uma ideia interessante: 'Você não precisa ser responsável pelo mundo em que vive'. Então eu desenvolvi um poderoso senso de irresponsabilidade como resultado do conselho de von Neumann. Isto fez de mim um homem feliz a partir de então." (DYSON, 2012, p. 62)

Assim, de olhos fechados para os desdobramentos sociais do seu trabalho matemático, von Neumann prosseguiu seus estudos, como colaborador do Projeto Manhattan e, pouco mais tarde, da fabricação da Bomba de Hidrogênio. Em 1944 von Neumann conheceu a máquina ENIAC, Electronic Numerical Integrator and Computer, cujo projeto havia 
sido iniciado um ano antes pelos cientistas John Eckert e John Mauchly (Estados Unidos) para computar trajetórias balísticas que exigissem cálculo matemático volumoso. Von Neumann passou a colaborar com essa equipe, já planejando o sucessor Eletronic Discrete Variable Automatic Computer (EDVAC). Em 1945 explodiram as bombas em Hiroshima e Nagasaki, terminou a II guerra, e em 1946, também o projeto Manhattan. Com o fim da guerra, as publicações a respeito da bomba ficaram proibidas de vir a público, mas aquelas referentes ao computador foram liberadas. Von Neumann publicou o "First draft of a report on the EDVAC" (NEUMANN, 2016), onde consta como único autor, e, omitindo nomes e o percurso anterior em equipe, bem como o suporte teórico concebido pelo matemático inglês Alan Turing, na década de 1930. Assim, passou a protagonizar a invenção do computador. Data de 1957 a morte de von Neumann por causa de problemas ocasionados por exposição à radioatividade. Falece sob proteção militar, para evitar que revelasse segredos de guerra. (DYSON, 2012).

Estas cenas de guerra trazem à tona questões relacionadas à produção de ciência e tecnologia, e a conjuntura (tempo e local) onde se desenrola o percurso desta produção. Os cientistas colocam em foco um elemento de interdisciplinaridade ao evidenciar a impossibilidade de uma ampla compreensão destas tecnologias sob um olhar puramente técnico, sem que sejam considerados confrontos, conflitos e angústias. Entretanto, não é somente por este aspecto que revivemos aqui estas cenas. Importa ressaltar, através da historicidade de artefatos e ideias, a forma como a interdisciplinaridade se manifesta também na configuração dos próprios artefatos tecnológicos, bem como na configuração das próprias teorias científicas. $\mathrm{Em}$ se tratando de artefatos computacionais esta interdisciplinaridade circunda a compreensão da informação e da representação. É nesse ponto que pretendemos traçar um diálogo entre a Ciência da Computação e a Ciência da Informação.

A guerra deixou chamou atenção para a falência do modelo de produção de ciências e tecnologias com base em um recorte em especialidades. A tecnologia de guerra colocou em evidência a impossibilidade de uma ciência recortada em disciplinas em dar conta das demandas daquele momento. Como já foi dito aqui, a segunda guerra mundial cedeu lugar à guerra fria, e sob o comando do Presidente Truman, os investimentos dos Estados Unidos na bomba de hidrogênio. Einstein foi à público, em vídeo mostrado no tv-show intitulado "Today with Mrs. Roosevelt" conduzido pela ex-primeira dama Eleanor Roosevelt (RODGERS, 1950), para alertar sobre os perigos do novo programa armamentista: "Se bem sucedido [o programa armamentista], um envenenamento radioativo da atmosfera, e portanto a aniquilação de qualquer vida na terra, está entre o leque de possibilidades técnicas." Em seguida, The Washington Post anunciou: "Einstein teme que a bomba de hidrogênio possa aniquilar qualquer vida", em 13 de fevereiro de 1950. 
Nesse interim, o ENIAC já rodava os cálculos da bomba de hidrogênio (DYSON, 2012).

A guerra fria coloca em evidência um novo cenário, uma cena híbrida. É uma guerra de cálculos de alta precisão, alta tecnologia. Mas não somente isso. As técnicas já não bastavam, como também já não bastava o elemento humano. O combate exige que piloto e avião constituam um único corpo, um híbrido máquina-homem. É uma ciência que não se efetiva no campo de saberes exatos nem tampouco no campo das humanidades, mas no encontro destes saberes. Demanda estudos psicológicos, compreensão das subjetividades, porque é uma guerra de instantes. A informação está no centro das atenções em virtude da demanda por tomadas de decisões repentinas, mudanças bruscas de cenários. A máquina não sabe lidar com a informação incompleta, falta a ela o "sexto sentido", a intuição, o "rompante". Diante deste cenário, o grande matemático Norbert Wiener, a quem nos referimos no início deste texto, adverte a urgência de estudar humanos e animais, neuro-ciência, organismos vivos, algo que necessita ser feito em operação conjunta - em diálogo - com matemáticas e físicas. Formam-se os grupos interdisciplinares de trabalho:

Tivemos a oportunidade de comunicar nossos trabalhos a nossos colegas, em particular ao Dr Aiken, of Havard, Dr von Neumann, of the Institute for Advanced Study and Dr Goldstine, das máquinas ENIAC e EDVAC na Universidade da Pensilvânia. Em toda parte encontramos a escuta acolhedora e o vocabulário dos engenheiros foi aos poucos se contaminando com termos do neurofisiologista e do psicólogo. (WIENER, 1985, p. 15).

É para esta a ciência que Wiener cunhou o termo "cibernética", informação sob múltiplos olhares:

O papel da informação e a técnica de medir e transformar informação constituem uma disciplina para o engenheiro, para o psicólogo, e para o sociólogo [...] São essas zonas de fronteiras das ciências que oferecem as mais ricas oportunidades ao pesquisador qualificado [...] Se um fisiologista que não entende matemática trabalha junto com um matemático que não entende fisiologia, o primeiro não vai conseguir formular seu problema em termos que o outro possa manipular e o segundo vai ser incapaz de expressar as respostas de forma que o primeiro possa entender. (WIENER, 1985 , p. 2). 
Wiener destaca a cibernética como um campo interdisciplinar, e parece ser justamente o fato de enxergar além das, e por entre as, disciplinas e especialidades, o que faz com que seu trabalho posterior passe a mostrar uma profunda responsabilidade social. As questões conjunturais que circundam a atividade do cientista passam a ser, para ele, tanto quanto a própria ciência, uma questão interdisciplinar, intrincada na compreensão da informação. Wiener deixa claro que as duas questões que já foram aqui comentadas - o processo de produção de ciência e tecnologia (que supostamente se daria numa esfera social), e a conformação do próprio fato científico ou artefato tecnológicos (que supostamente se daria no âmbito de uma disciplina ou técnica) - são de fato uma única questão: contexto e conteúdo não se distinguem, e se estabelecem em processo de co-construção em torno da compreensão da informação, a caracterização do campo da cibernética. Em "O uso humano de seres humanos - cibernética e sociedade", publicado em 1950, Wiener argumenta:

É a tese deste livro que a sociedade só pode ser compreendida através de um estudo das mensagens e meios de comunicação que lhe pertencem; e que no desenvolvimento futuro destas mensagens e meios de comunicação, as mensagens entre homens e máquinas, entre máquinas e homens, e entre máquina e máquina, estão destinados a desempenhar um papel cada vez maior. (WIENER, 1989, p.16)

Assim, não surpreende que, em 1946, Wiener tenha se rebelado contra a participação dos cientistas na guerra. Fazendo eco às vozes pacifistas publicou o artigo "Um cientista rebela-se" que registra o seguinte episódio: Ao pedido de um outro cientista por um artigo de sua autoria que poderia colaborar na construção de mísseis, Wiener responde com uma carta que marca sua recusa em qualquer contribuição em favor da ciência da guerra, e felicita a indisponibilização seus trabalhos anteriores:

Desde o término da guerra tenho lamentado altamente a grande porcentagem de esforço científico neste país que está sendo dedicado à preparação da próxima calamidade. Por isso, estou muito satisfeito ao descobrir que minha publicação "Extrapolação, interpolação, e filtragem de Séries Temporais Estacionárias" não está mais disponível para aqueles que produzem mísseis controlados. Não posso, naturalmente, 
fornecer-lhe nenhum conselho a respeito de onde encontrálos. (WIENER; PACH, 1983)

Outros dentre aqueles que estiveram na linha de frente, em posições estratégicas para viabilizar a guerra, foram forçados a repensar o momento pós-guerra. Vannevar Bush, diretor chefe do Escritório de Pesquisa e Desenvolvimento Científico dos Estados Unidos, responsável por cerca de 6000 cientistas em missões secretas, lançou a questão no American Monthly, em Julho de 1945. "As we may think", um manifesto, um apelo por uma nova postura frente à ciência para lidar com um novo tempo:

Esta não tem sido uma guerra de cientistas; tem sido uma guerra em que todos tiveram um papel. Os cientistas, enterrando sua antiga competição profissional na procura de uma causa comum, muito partilharam e aprenderam. Foi emocionante trabalhar em parceria eficaz. Agora, para muitos, isso parece estar chegando ao fim. Que farão agora os cientistas? [...] Foram os físicos os que mais violentamente ficaram de fora, que largaram suas atividades acadêmicas para a fabricação de dispositivos destrutivos bizarros, que tiveram de conceber novos métodos para suas atribuições imprevistas. Eles fizeram a sua parte nos dispositivos que tornaram possível jogar para trás o inimigo, trabalharam em esforço conjunto com os físicos de nações aliadas. Sentiram em si mesmos a celeuma da realização. Foram parte de uma grande equipe. Agora, em tempos de paz, perguntamos: onde encontrarão objetivos dignos do que eles têm de melhor? (BUSH, 1945, p. 101)

Diante do fenomenal avanço em tecnologias e ideias, Bush vislumbrou uma asfixia, risco de afogamento no excesso. Ele denunciou o perigo de perderem-se na montanha de pesquisas: "estamos sendo atolados à medida em que a especialização se estende. O investigador é escalonado por resultados e conclusões de milhares de outros cientistas conclusões que ele não consegue encontrar tempo para compreender, muito menos para se lembrar" (BUSH, 1945, p. 102). Bush vai além do diagnóstico e propõe o caminho: "a especialização torna-se cada vez mais necessária para o progresso mas os esforços para relacionar as disciplinas é proporcionalmente superficial" (BUSH, 1945, p. 102). É um marco seminal na institucionalização da documentação para permitir recuperação e acesso à informação. Ele verifica que a documentação deve acompanhar a própria evolução das ideias e tecnologias. Vislumbra uma ponte, um elo que permita transpassar as disciplinas para ligar as ideias. Aqui também 
se evidencia que a produção científica responde às demandas da vida, e portanto, contexto-conteúdo (informação-documentação) são indissociáveis. Assim como Wiener percebeu ao propor a Cibernética, Bush argumentou que a documentação é, tanto quanto a própria ciência, uma questão interdisciplinar, intrincada na compreensão da informação. Nascem, sob o mesmo elo da informação, duas ciências para o século XXI: Ciência da Computação, Ciência da Informação. Espantosamente, estão hoje separadas na divisão de saberes entre "exatas" e "sociais" (CONSELHO NACIONAL DE DESENVOLVIMENTO CIENTÍFICO E TECNOLÓGICO - CNPq, 2016).

Ainda na virada do século $X X$, várias técnicas de análise, organização e descrição, tais como a publicação da primeira edição da Classificação Decimal Universal e a proposta do uso da microficha padronizada para o trabalho de documentação, contribuíram para o surgimento de novas ideias e práticas no campo da documentação. Em 1895, Paul Otlet e Henri de La Fontaine já haviam criado na Bélgica o Instituto Internacional de Bibliografia, que em 1931, passou a se chamar Instituto Internacional de Documentação. Daqui emerge o termo "documentação". Mais tarde, em 1935, Otlet publicou sua obra pioneira: Traité de Documentation (OTLET, 1935), onde elaborou a noção de documentação, o que de certa forma antecipou questões referentes aos novos suportes de informação: o microfilme adquiriu importância e laboratórios de microfotografia passam a ser implantados em diversas instituições. São sinais da emergência de uma nova ciência, motivada pelas demandas por mecanismos mais elaborados de documentação para possibilitar o registro e a recuperação de informação. Vannevar Bush, a quem já nos referimos, argumentou que o esforço científico deveria ser concentrado em deixar o conhecimento humano mais acessível. Também em "As we may think", ele propôs uma máquina denominada Memex (termo resultante da junção das palavras "Memory" e "Index"), que deveria oferecer possibilidades de acesso rápido à informação. Segundo Pinheiro (2002, p. 9), "Bush teve clara percepção do elo entre informação, pesquisa e desenvolvimento, consequentemente, do seu valor político e estratégico, constatado pela participação do Estado em muitas das principais iniciativas de informação científica e tecnológica".

Vemos que a busca pela eficácia na documentação visando o registro e recuperação da informação demandou uma grande aproximação deste campo emergente com as tecnologias. O pioneiro Otlet, por exemplo, na década de 1930, olhava com entusiasmo aos avanços tecnológicos e referia-se ao conceito do "novo livro": "Cinema, fonógrafo, rádio, TV: estes instrumentos tomados como substitutos livro tornaramse, de fato, o novo livro, trabalham no grau mais poderoso para a difusão do pensamento humano". (OTLET, 1935, p. 429). Como já foi dito aqui, a segunda de guerra gerou uma evolução em termos de equipamentos e tecnologias, culminando no EDVAC, a máquina com programa residente, 0 computador que conhecemos hoje. Em 1949, surgiu a primeira copiadora 
xerográfica, o Rapid Selector, desenvolvida por Ralph Robert Shaw sobre ideias de Bush (SHAW, 1947; VARLEJS, 1999). Pouco antes, em 1947, havia surgido o primeiro curso de documentação nos Estados Unidos (School of Library Science da Western Reserve University - WRU).

Esta aproximação com as tecnologias deixou claro que, atingir um nível de documentação que permitisse o acesso e a recuperação de maneira razoável demandaria compreender não somente os mecanismos próprios da documentação, nem tampouco somente o assunto sobre o qual se documenta. Seria preciso abordar a conformação do conceito da informação, ou seja, as tensões entre o que é apresentado e o que se pretende comunicar, as incompletudes. Embora este tema tenha sido o foco dos estudos matemáticos da década de 1930 quando se percebeu a impossibilidade de um sistema formal em provar enunciados expressos na sua própria linguagem (GÖDEL, 1965), este não é um tema disciplinar (completamente encerrado no escopo da matemática). A incompletude era ânsia de expressão da sociedade daquele momento, e portanto, se fez notar em campos diversos. Por exemplo, manifestou-se nas angústias de Artaud, dramaturgo francês da década de 1930 (ARTAUD, 2006). Ao buscar um máximo de fidelidade na representação (neste caso, trata-se da encenação, representação em cena), ele se deparou com as impossibilidades da linguagem: o objeto sempre escapa à representação. Aflito, apelou para gemidos, gritos e barulhos, necessidade de expressão que ultrapassa os mecanismos da linguagem e faz um apelo ao híbrido, linguagem teatral misturada, não pura. Nas artes, anos mais tarde, o apelo ao híbrido se mostra também nos desenhos de Escher (http://www.mcescher.com/gallery/recognition-success/mobius-strip-ii/), expressão artística de uma construção matemática, a Banda de Möbius (KUBRUSLY, 2013), na qual não se pode decidir qual é o lado de dentro e o lado de fora. Hoje vemos as pesquisas recentes da computação operando com as limitações da linguagem e buscando representações satisfatórias mesmo na percepção da incompletude. Por exemplo, os mecanismos de busca através da internet almejam meios de extrapolar as potencialidades da sintaxe. Passam enriquecer as representações com informações contextuais e conjunturais de modo via ontologias, de modo a possibilitar resultados de busca mais efetivos (CAFEZEIRO et al., 2008). Ainda mais recentes são as pesquisas que se aliam a novas possibilidades de participação que só se efetivam no campo não formal: requisita-se a participação humana em situações onde o processamento maquínico não é possível ou é inviável. Daí, a computação como um híbrido homemmáquina, o campo recentemente chamado de "Computação Humana" (CAFEZEIRO et al., 2014)

\section{Paradoxos da informação}

Vamos verificar que, no percurso histórico da construção dos computadores e da computação, a informação figurou como a entidade 
sobre a qual os cientistas se debruçavam. Observamos uma constante tensão entre a representação e o que se pretende representar. O que está permanentemente em jogo é a compreensão da informação, como um conceito que se estabelece no confronto entre a forma (a expressão linguística) e o significado. É justamente no espaço aparentemente vazio entre estes dois extremos (de um lado, o que expressamos, de outro o que pretendemos expressar) que a informação se efetiva, e portanto este é um espaço produtivo onde se conformam computação e computadores. É aí que podemos constatar o hibridismo deste campo de saberes. É também aí que se situam os estudos da Ciência da Informação, incluindose a documentação, tarefa que não se efetiva satisfatoriamente sobre uma dicotomia (de um lado, a documentação, de outro o que pretendemos documentar). Verificar o quão produtivo é este espaço de aparente separação entre os extremos é o ponto de partida para uma interação mais vigorosa entre saberes como os das ciências da Computação e da Informação.

Nas primeiras décadas do século XX a matemática viveu um período de grandes desafios. O que se apresentava naquele momento, e que vinha instigando a mente daqueles matemáticos, eram questões que pareciam pôr em dúvida as bases de sustentação deste campo. A matemática se debatia com o mundo dicotômico e totalizador sobre o qual se assentava. Por um lado, o encontro do verdadeiro e falso expunha contradições intoleráveis. Ao mesmo tempo, o vazio entre o verdadeiro e falso expunha um espaço de incompletude, inalcançável à matemática, o que era, da mesma forma, intolerável a um pensamento que ambicionava a totalização. Tanto quanto qualquer outro meio de expressão (formal ou não formal, objetivo ou subjetivo), a matemática não escapou às traquinagens da linguagem: a representação nunca alcança o seu objeto.

Causou alerta à comunidade matemática uma questão apresentada em 1902 por Bertrand Russell, a quem já nos referimos aqui, o pacifista que viria a propor a Einstein a co-autoria no manifesto pelo desarmamento nuclear de 1955. Um certo modo de pensamento daquele momento e local (Europa do fim do século XIX) permitiu a Russell perceber uma inconsistência na Teoria dos Conjuntos. Assustado, reportou ao reconhecido matemático Gottlob Frege, em carta datada de 16 de junho de 1902:

Há apenas um ponto onde encontrei uma dificuldade. O colega diz que uma função também pode atuar como elemento indeterminado. Eu acreditava nisto, mas agora esta perspectiva parece-me duvidosa pela seguinte contradição. Seja w o predicado: para ser predicado, não pode ser predicado de si próprio. Pode w ser predicado de si próprio? A cada resposta o seu oposto segue-se. Portanto podemos concluir que w não é um predicado. Da mesma maneira, não existe nenhuma classe (como uma totalidade) de classes que, sendo cada uma tomada como uma totalidade, não pertença a 
si própria. Disto concluo que, sob certas circunstâncias, uma coleção definível não forma uma totalidade. (HEIJENOORT,1967,p. 124-125).

Era uma questão matemática evidenciada nos mesmos termos do paradoxo do mentiroso: "Minto!", uma formulação que remonta a Grécia antiga (Epimênides, século 6 a.C): ao assumir-se verdadeira, literalmente revela-se falsa, e vice-versa. É um contraponto entre a compreensão da expressão e sua forma linguística, um mundo semântico e um mundo sintático, a representação e o representado, duas facetas da linguagem que entram em colapso numa sentença auto-referente em presença da negação: "Minto!", isto é, "não falo a verdade agora".

A formulação de Russell: O conjunto de todos os conjuntos que não pertencem a si próprio pertenceria a si próprio? Admitindo-se que sim (a semântica), a propriedade de não pertencer a si próprio que define o conjunto (o sintático) implica que não. Admitindo-se que não (a semântica), a negação da propriedade de não pertencer a si próprio (o sintático) implica que sim. Daí a confusão que assombrou Bertrand Russell. O mundo da lógica clássica é dicotômico, e nele não se admite a conjunção dos extremos (verdadeiro e falso, sintaxe e semântica, representação e representado).

Ao mesmo tempo em que as exigências de exatidão e certeza repudiavam os paradoxos, o ambiente científico era assentado sobre uma matemática que se reconhecia completa, ou seja, esperava-se que qualquer a sentença expressa na linguagem formal da matemática correspondesse uma prova de sua veracidade ou falsidade (é comum dizermos "a sentença tem prova" quando há uma prova de que é verdadeira e "a sentença não tem prova" quando há uma prova de que é falsa). Em 1931, trabalhando sobre estes pressupostos, o matemático Kurt Gödel percebe a impossibilidade de um sistema matemático ser ao mesmo tempo completo e livre de contradições. É o que chamamos de Incompletude (GÖDEL,1965). Para isto, Gödel trabalhou com a seguinte sentença: "Esta sentença não tem prova!" Novamente, uma expressão matemática do paradoxo do mentiroso. Gödel representou esta sentença na linguagem da lógica, e reproduziu nesta linguagem o seguinte argumento: sendo a sentença falsa, concluímos que não é verdade que ela não tenha prova e, portanto, ela tem prova, daí é verdadeira, uma contradição. Por outro lado, se a sentença é verdadeira, então ela mesma constitui o exemplo de que há na matemática uma sentença que não pode ser provada (nem verdadeira nem falsa), uma incompletude. Daí, não é possível que um sistema matemático expressivo o suficiente para representar sentenças como esta seja, ao mesmo tempo, completo e consistente (GÖDEL, 1965).

Decepcionados, mas conformados com a incompletude da matemática, os matemáticos se debruçaram então sobre o problema de 
definir o escopo da matemática, ou seja, buscar mecanismos matemáticos para representar o conjunto das expressões matemáticas que poderiam ser provadas. Isto, em outras palavras, significa dizer, definir o conceito do que vem a ser "mecânico", "calculável" ou "computável".

Em 1936 o matemático inglês Alan Turing concebeu um dispositivo teórico para representar este conceito. Ele imaginou um cabeçote de leitura que se deslocava sobre uma fita de extensão ilimitada em um dos lados, e dividida em quadras adjacentes. Sobre cada uma dessas quadras o cabeçote poderia gravar apenas um dos símbolos " 0 " ou " 1 ". A máquina funcionaria numa sucessão de passos, uma máquina dedicada a uma única tarefa definida no controle. A este dispositivo damos hoje o nome de "Máquina de Turing" (TURING, 1936). Observe que a Máquina de Turing opera sobre símbolos (e não sobre números, que são símbolos com uma interpretação matemática fixada). Portanto a sequência impressa na fita no início do processamento, bem como a que resulta ao final dependem de uma interpretação humana, ou seja, o processamento da Máquina de Turing se dá na potência entre o símbolo e suas possibilidades de significação, justamente o domínio onde se conforma a informação.

Num salto de abstração, Turing percebeu que as instruções que especificavam o controle do dispositivo poderiam também ser expressas apenas com símbolos " 0 " e " 1 ". Assim, todo o controle seria descrito como uma sequência finita de símbolos. A máquina poderia operar com duas fitas, a primeira procederia como antes, alocando entrada e saída e a outra guardaria a expressão em dígitos binários 0 e 1 do controle, tendo cada fita o seu próprio cabeçote de leitura e operação independente. Assim, Turing definiu um dispositivo teórico, que hoje chamamos de "Máquina Universal de Turing" com a capacidade de receber o controle de qualquer outra Máquina de Turing, e se comportar como ela. (TURING, 1936). É o computador! Observe que há aqui outro confronto: uma sequência de bits ora é vista como um programa, ora como um dado. Ainda nos dias de hoje, consideramos que um dispositivo é um computador se ele é capaz de operar sobre uma sequência de bits ora como dado (por exemplo, baixamos, copiamos, apagamos arquivos de programas), ora como programas (executamos programas).

Da mesma forma que o computador que conhecemos hoje, a Máquina Universal tem a capacidade de receber um programa e executálo seja lá qual for o seu propósito: é uma máquina de propósito geral. Assim como a Máquina Universal de Turing, o computador dos dias de hoje efetua também um processamento simbólico operando sobre níveis (baixo e alto) de tensão elétrica que chamamos de bit zero e bit um. Novamente aqui há um confronto entre a forma e o significado (representação e representado). Imaginamos que os símbolos que escolhemos para representar os níveis de tensão são os números zero e um. Construímos toda a aritmética sobre esta interpretação, e daí os números inteiros, os números reais, os caracteres e tudo o mais. Novamente, é a potência entre o símbolo e suas possibilidades de 
significação (o campo da informação) que dá existência ao mundo computacional. E é este, por sua vez, que modifica e reconfigura o mundo em que habitamos hoje: são os cálculos que pagam os nossos salários, as conversas que viabilizam as nossas relações, as compras que fazemos, e muitas outras coisas da nossa vida contemporânea, apoiadas sobre bits.

O termo bit surgiu em 1945 na equipe de von Neumann, no estudo de possíveis contribuições ao ENIAC. Von Neumann conseguiu unir ao projeto de Eckert e Mauchly as sugestões teóricas de Alan Turing. Ele propôs a introdução da aritmética binária em substituição da aritmética digital (NEUMANN, 2016, p. 6), e o que chamou de "programa residente", ou seja, o armazenamento de dados e programas na memória (NEUMANN, 2016, p. 37). Construído desta maneira, o EDVAC materializou a Máquina Universal de Alan Turing, numa arquitetura de máquina posteriormente nomeada "arquitetura de von Neumann" e operou entre 1849 e 1961.

\section{Institucionalização das ciências da Computação e da Informação e o surgimento do novo campo Sistemas de Informação}

A partir dos anos sessenta, já com o computador estabelecido e produzido comercialmente, iniciaram-se os esforços de institucionalização daquilo que seria o campo de saber científico relacionado aos computadores. Como vimos, também o campo da documentação contava com um suporte tecnológico surpreendente. Os primeiros argumentos no sentido da institucionalização de uma ciência relacionada à documentação vieram no bojo de reflexões sobre o papel da ciência e do cientista em concepções híbridas e interdisciplinares, acompanhadas das projeções tecnológicas para dar suporte ao campo emergente. Não surpreende que as discussões a respeito da institucionalização de ambos os campos tenham se estabelecido em torno do conceito de informação.

Porém, a institucionalização de uma ciência demanda a delimitação de um território, uma categorização de saberes. Não havendo a urgência de um problema (no caso, a guerra) em torno do qual os saberes sejam reivindicados, o hibridismo e interdisciplinaridade não mais se fazem evidentes. Embora almejados no momento de concepção destes campos, hibridismo e interdisciplinaridade se enfraqueceram no processo de institucionalização, cedendo espaço a abordagens centradas em metodologias e técnicas, que ajudam a fortalecer a concepção de cada uma destas disciplinas e como ciências.

Além disso, década de 60 mostrava um outro panorama com relação às demandas sociais e governamentais dos países ricos. O satélite russo Sputnik, enviado ao espaço em 1947 lançou os Estados Unidos na corrida aos programas de educação científica e exploração espacial, passando o governo a encarar a informação científica e tecnológica como fator estratégico para superar a ameaça no mundo polarizado da guerra fria. Em 1963, o físico Steven Weinberg, representante do Comitê Consultor da 
Ciência para o presidente dos Estados Unidos publicou um relatório endereçado a cientistas e engenheiros, em cujo prefácio constavam palavras vindas da Casa Branca: "ciência e tecnologia fortes são uma necessidade nacional e uma comunicação adequada é um pré-requisito para ciência e tecnologia fortes". O relatório "Ciência, Governo e Informação" (WEINBERG, 1963) invocou, já no subtítulo a responsabilidade do governo na transferência da informação no mesmo grau e espírito em que aceitavam a responsabilidade da pesquisa e do seu desenvolvimento. Surgia uma outra dinâmica no "fazer científico", inspirada no modelo de grandes financiamentos estatais em virtude da guerra. Aos poucos, cientistas bem-sucedidos deixariam os laboratórios e para assumir o "escritório", passando a exercer funções gestores da ciência: "Em certo sentido, cada cientista individualmente ou tecnólogo é um gerente de pesquisa. No início de uma nova pesquisa deve decidir sobre sua estratégia (incluindo a alocação de seus recursos pessoais)" (WEINBERG,1963, p. 13). A consequência direta foi a criação de um comitê com este propósito: O Committee on Scientific and Technical Information (COSATI), bem como agências gestoras da ciência. Um outro Weinberg, físico nuclear também atuante em tempos de guerra, cunhou o termo "big Science" para se referir a este novo o fazer científico suportado financeiramente pelo estado, com vultuosos investimentos, e cientistas gestores. Defendeu Alvin Weinberg: "Big Science está aqui para ficar, mas temos ainda de fazer rígidas escolhas financeiras e educacionais que ela demanda." (WEINBERG, 1961, p. 161) Assim, o modelo da guerra contribuiu para inaugurar um "novo modelo de organização da produção dos conhecimentos, em grandes programas de pesquisa 'orientados por missão', os quais, para serem viabilizados, requerem a participação de mais de um grupo e instituição de pesquisa, assim como a coordenação efetiva entre o governo federal, a universidade e o setor privado, interagindo de modo cooperativo." (GOMEZ, 2006, s.p.). É um modelo que ainda hoje persiste inclusive no Brasil, a exemplo do seminário promovido pela Sociedade Brasileira de Computação para estabelecer as grandes missões da computação para o desenvolvimento nacional:

O Seminário Grandes Desafios da Pesquisa em Computação no Brasil foi concebido a partir de iniciativas semelhantes realizadas em outras partes do mundo [...]. Seu objetivo não é apresentar resultados de pesquisas em andamento, mas sim definir questões de pesquisa que serão importantes para a ciência e para o país no longo prazo. (SOCIEDADE BRASILEIRA DE COMPUTAÇÃO - SBC, 2006).

Ao final da década de 60 os programas computacionais vinham se tornando muito extensos e complexos, e como, naquela época, em função do alto custo, computadores eram usados essencialmente para resolver problemas de risco e situações de segurança nacional (dos países ricos), a 
presença de erros nos sistemas computacionais era anunciada como uma grande ameaça e risco de colapso total. Supondo a iminência da catástrofe, a aliança militar Organização do Tratado do Atlântico Norte, OTAN, convocou, em 1968, uma importante conferência em Garmisch, Alemanha, onde estiveram presentes mais de 50 pessoas de 11 países, dentre usuários, grandes fabricantes e renomados professores universitários, todos preocupados com o destino da produção de software: "Uma questão de vida e morte" (NATO, 1968, p. 120). Mais tarde o sociólogo Donald Mackenzie mostrou que os riscos não eram tão grandes quanto se falava na época (MACKENZIE,1996), no entanto, a conferência marcou o estabelecimento da área da Computação. Assim, a discussão ultrapassou o software adentrando por questões de currículo universitário e institucionalização do campo. Evidenciavam-se os esforços afirmativos de uma área emergente, que, acotovelando-se com outras já estabelecidas por tradições seculares, como a matemática e a física, buscava merecer a designação de "ciência". Pesquisadores se empenharam com euforia em fazer da computação um campo purificado e bem delineado, a despeito do percurso histórico de construção interdisciplinar a que nos referimos aqui.

A institucionalização da Ciência da Computação se efetivou sobre o embate entre dois polos. Um respeitável grupo da comunidade da computação, incluindo Djkstra ${ }^{1}$, Hoare ${ }^{2}$, Wirth $^{3}$, enxergou na exatidão matemática a porta de entrada, o passaporte para o mundo das "comprovadas certezas científicas", resultando em um esforço declarado de posicionar a computação como Ciências Exatas:

Programação de computadores é uma ciência exata uma vez que todas as propriedades de um programa e todas as consequências de execute-lo em um dado ambiente podem, em princípio, ser encontradas no texto do próprio programa por meios do puro raciocínio dedutivo. (HOARE, 1969, p. 1).

Possivelmente Hoare teve o cuidado de dizer "em princípio", porque sabemos que, uma vez posto para rodar em um ambiente funcional, não se pode mais isolar o programa do mundo, e o sistemas fica exposto a intervenções de tipos imprevisíveis, algo fora do escopo das ciências exatas.

\footnotetext{
1 Edsger Dijkstra foi um pesquisador holandês responsável por importantes contribuições à Ciência da Computação. Por ocasião da conferência de 1968, Djkstra era, reconhecidamente, um influente nome na área, tendo recebido o Prêmio Turing, em 1972. Djkstra veio a falecer em 2002, aos 72 anos em decorrência de câncer.

2 Atualmente C.A.R. Hoare é professor emérito da Universidade de Oxford e pesquisador Sênior da Microsoft Research em Cambridge. Hoare recebeu o Prêmio Turing em 1980, o Prêmio Kyoto em 2000 e a medalha John von Neumann em 2011. O título de nobreza britânica "sir" advém de suas contribuições ao ensino da computação. Hoare não esteve presente na conferência de Garmisch em 1968, mas marcou posição na edição seguinte, no ano de 1969, em defesa das provas formais de correção de programas.

${ }^{3}$ Niklaus Wirth foi o criador da linguagem Pascal, ainda hoje muito utilizada no ensino de programação. Wirth foi ganhador do Prêmio Turing em 1984 e do Prêmio SIGPLAN em 2007. Está aposentado desde 1999.
} 
Opondo-se à matematização do software, outro grupo encabeçado por Alan Perlis ${ }^{4}$ considerava a computação como um campo híbrido, ultrapassando o escopo de ciências exatas: "Podemos ver se aproximando a demanda por sistemas que permitem a colaboração, por exemplo, entre engenharia e gerenciamento da informação." (NATO, 1969, p. 135) Perlis considerava a relação entre humanos e computador como uma dependência simbiótica. Alguns anos mais tarde foi bastante criticado pela frase: "Para entender um programa você precisa se tornar tanto máquina quanto programa". (PERLIS, 2016,s. p.).

A disputa se repetiu na conferência da OTAN do ano seguinte, prevalecendo a tendência de fortalecer o caráter "científico" pela sua aderência à matemática (NATO, 1970). Este debate influenciou até mesmo a escolha do nome para a ciência emergente. A maior parte dos cientistas presentes preferiu o termo "Ciência da Computação", ao perceber que "Informática" enfatizaria a informação, uma noção imprecisa, que escapa à exatidão matemática, ou "Engenharia da Computação", que ressaltaria um caráter empírico fortalecendo o "fazer" sobre o "raciocinar".

Até recentemente, a tendência à matematização prevaleceu nos currículos universitários do campo da computação. Nos currículos de Ciência da Computação, ainda hoje percebe-se a forte presença de físicas e matemáticas em detrimento de conhecimentos relacionados à informação, sociedade, comportamento, política e cultura, e a sugestão de que a matemática é a garantia da confiabilidade dos sistemas computacionais persistiu, ainda no século XXI, justificando a criação de vultuosos e ambiciosos projetos, alinhada com a política científica sugerida por Weinberg:

$O$ ideal do software correto tem sido o objetivo da pesquisa em Ciência da Computação. [...] Este artigo argumenta que o momento é propício para embarcar em um projeto internacional de Grande Desafio para a construção de um verificador de programa que usaria prova lógica para a verificação automática da correção de programas. [...] 0 projeto irá fornecer a base científica de uma solução para muitos dos problemas de erro de programação que afligem todos os construtores e usuários de software hoje. (HOARE; MISRA, 2005, p. 1).

\footnotetext{
${ }^{4}$ Alan Perlis pode ser considerado um dos fundadores da Ciência da Computação. Era, já em 1968 um pesquisador renomado, de formação fortemente matemática, presidente eleito da Association for Computing Machinery e primeiro ganhador do prêmio Turing, em 1966, por suas contribuições na área de Linguagens de Programação. Foi Perlis quem proferiu as palavras de abertura da conferência de 1968: "Porque programamos este encontro? Porque concordamos em participar?" e se mostrava bastante mobilizado pelas questões do ensino e qualidade do software. Alan Perlis faleceu em 1990 aos 68 anos, vítima de esclerose múltipla.
} 
Porém, a despeito do esforço destes influentes teóricos em insistir na compreensão da computação como uma disciplina das ciências exatas, a década de 1970 mostrou os primeiros sinais de uma tendência oposta, que viria a se fortalecer no século XXI. Alan Perlis abriu o caminho. Em 1974 ele publicou um artigo que deixou claro desde o título a compreensão da computação como uma área de encontro de saberes: "Processos Sociais e Provas de Teoremas e Programas". O artigo não somente argumentava a impossibilidade das provas formais em garantir por si só a correção dos sistemas computacionais, mas também antecipou a constatação de que processos sociais então emergentes, como reuso de código, programação em pares, código aberto, seriam os recursos fundamentais para garantir a confiabilidade de sistemas:

Uma vez que o requerimento para um programa é informal e o programa é formal, deve haver uma transição, e a própria transição deve, necessariamente, ser informal. [...] Será que os seguidores da verificação formal perderam de vista as origens informais dos objetos formais com os quais eles lidam? Seria isso a garantia de que suas formalizações são de alguma forma incontestáveis? Confessamos a nossa confusão e consternação. (MILLO; LIPTON; PERLIS, 1979, p. 275).

O artigo provocou a ira dos cientistas a favor da matematização da computação e desencadeou um caloroso debate na seção de cartas da importante revista Association for Computing Machinery (THE ACM FORUM, 1979). Hoje vemos que este artigo antecipou questões que somente através do nível de colaboração que a Internet possibilitou nos foi possível perceber claramente, e retomar a percepção da computação como um campo híbrido através do estabelecimento da especialização em Sistemas de Informação. Ao final do século $X X, a$ Sociedade Brasileira da Computação passou a aderir a esta tendência, já preparando para o século XXI perspectivas sociotécnicas para uma nova graduação em computação: "[...] Desta forma, sistemas de informação são componentes complexos, que podem ser descritos em termos de suas dimensões organizacional, humana e tecnológica, e exigem uma abordagem multidisciplinar no que diz respeito a sua otimização e a resolução dos problemas que Ihes são pertinentes" (SBC, 1999). Eis aqui uma porta aberta para a efetivação de um diálogo mais vigoroso com a ciência irmã.

\section{Considerações finais}

Trazemos aqui uma modesta contribuição no sentido de retomar uma interação mais elaborada entre os saberes da Ciência da Computação (em particular, dos Sistemas de Informação) e da Ciência da Informação. É importante que esta aliança entre saberes ultrapasse uma abordagem que vem se tornando usual, a "via de mão dupla", onde entende-se que a 
computação pode contribuir com a Ciência da Informação no sentido de oferecer mecanismos automatizados para o armazenamento, manuseio e recuperação da informação, e que inversamente, a Ciência da Informação pode contribuir com a computação no sentido de propor modelos de representação da informação que possibilitem um arranjo lógico mais elaborado sobre o qual os sistemas computacionais possam agir. Essas abordagens complementares são aderentes à categoria já superada de um modelo de ciências aplicadas, em que uma ciência se coloca como provedora de serviços à outra. O que queremos enfatizar aqui é a possibilidade um modelo de co-produção, em que as ciências colaboram na conformação dos conceitos que as fundamentam. É um modelo de interdisciplinaridade porque confraterniza traduções provenientes de ambas as disciplinas sobre um objeto compartilhado por ambas, nesse caso, a informação. Esta abordagem se torna possível no momento em que se deixa transparecer a historicidade da construção dos conhecimentos. Quando se permite verificar as questões da vida que as formulações teóricas se propuseram a resolver, torna-se possível perceber a atuação de diversas disciplinas sob um mesmo objeto, e a partir daí, efetivar a colaboração entre os saberes. O campo de Sistemas de Informação se diferencia da Ciência da Computação porque reivindica uma abordagem sociotécnica. Isto significa perceber "técnicas" e "sociedade" como um mesmo corpo, em co-construção, para daí conceber computação, computadores e sistemas como atividades inerentes às organizações sociais (SBC,1999). É portanto, um campo que busca se situa na fronteira do que se diz "ciências exatas" e as "humanidades". Aberto à interação, é um campo propício ao diálogo com a Ciência da Informação.

\section{Referências}

ARTAUD, A. O teatro e seu duplo. São Paulo: Martins Fontes, 2006.

BARROS, F. S. O Manifesto Russell-Einstein e as Conferências Pugwash. Física na Escola, Rio de Janeiro, v. 6, n. 1, p. 15-22, 2005.

BENVENISTE, E. O homem na Linguagem. Lisboa: Veja,1992.

BUSH, V. As we may think. Atlantic Monthly, v. 176, n. 1, p. 101-108, 1995.

CAFEZEIRO, I. et al. Ontologias: interoperabilidade, contexto, computação ubíqua. In: SEMINÁRIO DE PESQUISA EM ONTOLOGIA NO BRASIL, Niterói. Disponível em:

http://www.lbd.dcc.ufmg.br/colecoes/ontobras/2008/006.pdf>, 2008.

CAFEZEIRO, I. et al. A knowledge-construction perspective on human computing, collaborative behavior and new trends in system interactions. In: LECTURE Notes in Computer Science. 851ed. [s.l.]: Springer International Publishing, 2014. p. 58-68. 
CONSELHO NACIONAL DE DESENVOLVIMENTO CIENTÍFICO E TECNOLÓGICO (CNPQ). Tabela de Áreas do Conhecimento. 2016. Disponível em: $<$ http://www.cnpq.br/documents/10157/186158/TabeladeAreasdoConhecimento.pdf $>$ Acesso em: 30 jan. 2016.

DYSON, G. Turing's cathedral: the origins of the Digital Universe. London: The Penguin Group, 2012.

EINSTEIN, A. Einstein's letter to president Roosevelt:1939. 2016. Disponível em: <http://www.atomicarchive.com/Docs/Begin/Einstein.shtml>. Acesso em: 30 jan. 2016.

EINSTEIN, A. Como vejo o mundo. Rio de Janeiro: Nova Fronteira, 1981.

EINSTEIN, A.; RUSSELL, B. Enstein-Russell manifesto. 2016. Disponível em: <http://www.atomicarchive.com/Docs/Begin/Einstein.shtml>. Acesso em: 30 jan. 2016.

GÖDEL, K. On formally undecidable propositions of principia mathematica and related systems. In: DAVIS, M. (Org). The undecidable: basic papers on undecidable propositions, unsolvable problems and computable functions. New York: Dover Publications, 1965. p. 4-38.

GOMEZ, M. N. G. As relações entre ciência, estado e sociedade: um domínio de visibilidade para as questões da informação. Ci. Inf., Brasília, v. 32, n. 1, p. 60-76, Apr. 2003. Disponível em: <http://www.scielo.br/scielo.php?script=sci_arttext\&pid=S0100$19652003000100007 \&$ Ing=en\&nrm=iso $>$. Acesso em: 4 jan. 2016.

HEIJENOORT, J. From Frege to Gödel. Cambridge, Massachusetts: Harvard University Press, 1967.

HOARE, C. A. R.; MISRA, J. Verified software: theories, tools, experiments vision of a grand challenge project. In: MEYER B.; WOODCOOK J. (Eds.). IFIP TC 2/wg 2.3, VSTTE 2005, 1., Zurich, 2005. Proceedings... Zurich: LNCS, Springer 2005. v. 4171. p. 1-18.

HOARE, C. A. R. An axiomatic basis for computing programming. Communications of the ACM 12, v. 10, p. 576-580, 1969.

KUBRUSLY, R. Costurando uma fita na cabeça: um ensaio sobre a invenção da pessoa. In: FRADE, C.; PAPE, C.; MANHÃS, R. (Orgs.). Ética, arte, ciência e filosofia. Rio de Janeiro: Decult/Comcultura, 2013. p. 7588.

MACKENZIE, D. A. Knowing machines: essays on technical change. Cambridge, MA: The MIT Press, 1996.

MILLO, R. A.; LIPTON, R. J.; PERLIS, A. Social process and proofs of theorems and programs. Communications of the $A C M$, v. 22, n. 5, p. 271280, 1979. 
NATO. Report of a conference sponsored by the NATO Science Committee. Garmisch, Germany, 7-11 Oct. 1968. Brussels: Scientific Affairs Division; NATO $1969 . \quad$ Disponível em: $<$ http://homepages.cs.ncl.ac.uk/brian.randell/NATO/nato1968.PDF>. Acesso em: 30 jan. 2016.

NATO. Report of a conference sponsored by the NATO Science Committee. Rome, Italy, 27-31 Oct. 1969. Brussels: Scientific Affairs Division, NATO, 1970. Disponível em: < http://homepages.cs.ncl.ac.uk/brian.randell/NATO/nato1969.PDF>. Acesso em: 30 jan. 2016.

NEUMANN, J. First draft of a report on the EDVAC. 2016. Disponível em: $<$ http://www.virtualtravelog.net/wp/wp-content/media/2003-08-TheFirstDraft.pdf $>$.

Acesso em: 30 jan. 2016.

OTLET, P. Traité de documentation: le livre sur le livre, théorie et pratique.Bruselles, Belgium: Mundaneum,1934.

PERLIS, A. Epigrams on programming. SIGPLAN Notices, v. 17, n. 9, p. 713, September 1982.

PINHEIRO, L. V. R. Gênese da Ciência da Informação ou sinais anunciadores da nova área. In: PINHEIRO, L. V. R. O campo da Ciência da Informação: gênese, conexões e especificidades. João Pessoa: UFPB, 2002. p. 61-86.

RODRIGUES, N. O óbvio ululante: primeiras confissões. São Paulo: Companhia das Letras, 1993.

ROOSEVELT, F. D. President's Roosevelt response to Dr Einstein. 2016. Disponível em: <http://www.atomicarchive.com/Docs/Begin/Roosevelt.shtml>. Acesso em: 30 jan. 2016.

RODGERS, D. (Dir.). Today with Mrs Roosevelt [1950-02-12]. United States: NBC Television Network, 1950.

SHAW, R. R. The rapid selector. Journal of Documentation, v. 5, n. 3, p.164-171, 1949.

SOCIEDADE BRASILEIRA DE COMPUTAÇÃO (SBC). Relatório do Seminário Grandes Desafios da Pesquisa em Computação no Brasil. São Paulo: Sociedade Brasileira de Computação, 2006. Disponível em: $<$ http://www.gta.ufri.br/rebu/arquivos/SBC-Grandes.pdf> Acesso em: 30 jan. 2016.

SOCIEDADE BRASILEIRA DE COMPUTAÇÃO (SBC). Currículo de Referência da Sociedade Brasileira de Computação. 1999. Disponível em: <http em: http://www.sbc.org.br/educacao/>. Acesso em: 30 jan. 2016.

THE WASHINGTON POST. Einstein Fears Hydrogen Bomb Might Annihilate 'Any Life', 13 Feb. 1950. 
THE ACM FORUM. Comments on social processes and proofs. Communications of the ACM, v. 22, n. 11, Nov. 1979.

TURING, A. On computable numbers, with an application to the Entscheidungs proble". Proceedings of the London Mathematical Society, Series 2, n. 42, p. 230-265, 1936.

VALERJS, J. Shaw and the rapid selector. 1999. Disponível em: $<$ http://webdoc.sub.gwdg.de/ebook/s/2001/chf/www.chemheritage.org/historicalservi ces/asis documents/asis98 varlejs.pdf > Acesso em: 30 jan. 2016.

WIENER, N. Cybernetics or control and communication in the animal and the machine. Cambridge, MA: The MIT Press, 1985.

WIENER, N. The human use of human beings: cybernetics and society. London: Free Association Books, 1989.

WIENER, N.; PACH, L. From the archives. Science, Technology, \& Human Values, v. 8, n. 3, p. 36-38, 1983. Disponível em: $<$ http://www.jstor.org/stable/688755 $>$. Acesso em: 30 jan 2016.

WEINBERG, S. Science, government and information: the responsibilities of the technical community and the government in the transfer of information. A Report of the President's Science advisory commitee. Washington: The White House, January 10,1963.

WEINBERG, A. M. Impact of large-scale science on the United States. Science, v. 134, n. 3473, 21 July 1961. 